\title{
A CIVILIZATIONAL DIALOGUE PERSPECTIVE FOR A GLOBAL FAMILY
}

\author{
Elisabet Sahtouris ${ }^{1, *}$ \\ ${ }^{1}$ Chaminate University of Honolulu, USA.
}

\section{Prologue}

Surely we live in the most exciting, fascinating and challenging, if also the most complex, frightening and confusing time in human history. Even the most affluent and comfortable people in the world now face the sudden confluence of the biggest global crises ever-in energy, finance and global warming, not to mention the continuing crises of poverty, war, ecosystem destruction, air, water and soil pollution, etc.

As these great global crises converge upon us with terrifying speed and impact, we seem to be numbed to the staggering amounts of new money printed for government bailouts of banks and businesses in the West while public debt and unemployment soar. In the East we fear the loss of newly found wealth and newly created or entered markets. Everywhere we are paralyzed by the dire warnings of scientists about desertification, temperature and sea level rise that governments are reluctant to address, along with the enormous waste of massive resources in many places on warfare.

One might think that we humans, facing such crises, would be putting our heads together and bringing all our human and material resources to bear on peaceful dialogue and cooperative economic/ecological sustainability, as one would expect an intelligent species with the capacity of foresight to do. Yet the world's political and economic leadership largely clings to the status quo, tinkering a bit here and there, but unable effectively in this process.

More than two decades ago, In the 1980s, writing my book EarthDance, Elisabet Sahtouris (2009): Living Systems in Evolution on a Greek island, I began it with the following words: Everyone knows that humanity is in crisis, politically, economically, spiritually, ecologically, any way you look at it. Many see humanity as close to suicide by way of our own technology; many others see humans as deserving God's or nature's wrath in retribution for our sins. However, we see it, we are deeply afraid that we may not survive much longer. Yet our urge to survival is the strongest urge we have, and we do not cease our search for solutions in the midst of crisis.

The proposal made in this book is that we see ourselves in the context of our planet's biological evolution, as a still new, experimental species with developmental stages

\footnotetext{
* Corresponding author: elisabet@sahtouris.com eISSN: 2636-9265 CUniversiti Malaya Centre for Civilisational Dialogue, 2021 DOI: https://doi.org/10.22452/KATHA.vol17no1.3
} 
that parallel the stages of our individual development. From this perspective, humanity is now in adolescent crisis and, just because of that, stands on the brink of maturity in a position to achieve true humanity in the full meaning of that word. Like an adolescent in trouble, we have tended to let our focus on the crisis itself or on our frantic search for particular political, economic, scientific, or spiritual solutions depress us and blind us to the larger picture, to avenues of real assistance. If we humbly seek help instead from the nature that spawned us, we will find biological clues to solving all our biggest problems at once. We will see how to make the healthy transition into maturity.

Now the crises have grown to nearly overwhelming proportions, but fortunately the help I promised is even more available to us because science has not stood still and has brought us even clearer views of how nature solved critical problems in the course our own human evolution. In particular, we can see more clearly into the amazing nanoworld of our own cells and genomes, with new clues about how to make our own financial system and economy work as well at the global-social scale as it does in our bodies!

Furthermore, we increasingly recognize that we are not helpless victims of circumstance, but that we individually and collectively create the situations in which we live out of our beliefs, our values and ideas. This recognition is essential to acceptance of individual responsibility for our collective condition. Every building, every war, every agricultural practice, every airplane, every constitution, every industry, every medical practice and every piece of music or other art, began in a human soul/mind and was then translated into our physical world. Even choices we make shopping now affect the whole world.

From my perspective, while in some ways our adolescent crisis has deepened with recent financial/economic tsunamis, we can also clearly see the first steps toward species maturity, notably in the amazingly fast development of the Internet and iPod, permitting instantaneous and global dialogue and decision- making, including the weaving together of over a million grassroots NGOS working to make life better for people and their ecosystems on the ground. While banking and corporate giants representing our immature phase topple like dominoes, we the people are taking on the responsibilities of mature citizenship, self-governance, clean green technologies and other means to a more workable future. Yes, we can live better, even on a hotter planet!

\section{The Call to Cooperation}

For the first time, ordinary people as well as leaders are having instant conversations around the entire planet. Our conversations are about huge global issues as well as myriad personal and local matters. Whatever they are about, these people-to-people conversations are changing our world. We have all become decision makers making a difference by sharing our information, so we must do our best to make sense of our world, to understand what we are acting upon in order to make intelligent choices. 
Economic issues and global warming call upon humanity to cooperate, yet we are held up by continuing hostilities-expensive for most people and profitable for few-or bureaucracies or wanting to quietly maintain our own status quo despite the neediness of others or feeling somehow inadequate to the task.

Business is changing on large scales; the western domination of recent centuries is being rebalanced by eastern development though the span of wealth among people of different social strata is wider than ever in most parts of the world. Population demographics-ethnic, religious and age distributions-are shifting everywhere. A growing pool of experienced and active older global citizens can see on longer timescales while rapidly increasing numbers of young global citizens are testing their wings in dialogue and decision-making activities across the distance-eliminating Internet.

Technology has brought us wondrous advances while also making dangerous advances into arenas of life that are still poorly understood, putting our food supplies and bodies at risk. Science and religion battle even in courts of law over how our world came to be, yet movements are growing that integrate these opposing views harmoniously. While many people and organizations are actively engaged in positive change, many others are losing hope as they watch the world's seemingly insurmountable crises pile one on another. It is an amazing stew of events that churns the world and dizzies our minds with its complexity.

For me, as an evolution biologist, the key to understanding this complexity, so rife with contradictions, has been to observe humanity, along with other species, in the great evolutionary trajectory of planet Earth. As I engaged in this exercise, I came to see an intelligent harmony working itself out in nature again and again, more often than not in the midst of crisis, chaos, confusion.

Earth is a great living being with a common gene pool shared throughout biological evolution by all its species, from the lowliest bacterium to the greatest mammoths and whales. Further, the Cosmos, as I see it, is a vast living, evolving system. This view of things took me far beyond what I was formally taught as a western scientist, yet I gradually discovered many other scientists independently coming to see things this way. Eventually I realized that the whole scientific story of How Things Are was evolving, just at the time when humanity was evolving from immature competition to mature cooperation.

Indeed, this is an exciting time, and the most exciting thing about it is that every one of us can understand our world and be active change agents within it for a better, more cooperative, and peaceful future. 


\section{Western Science, Society and Religion}

Before I get to biology and what we can learn from it, let me say a little about the evolution of western science. All cultures need, and have, creation stories to give them understanding, meaning and purpose for human life. Historically, most tellers and keepers of creation stories have been religious priesthoods from the most ancient times to the present. As we know from the history of recent centuries, a traditional alliance between Church and State in Europe gave way to an alliance of Industry and Science. The Enlightenment together with this alliance in turn gave rise to secular nation states in which Church and State were intentionally separated. Scientists were then given the mandate to tell their 'creation story' as the official story of How Things Are in our cosmos and world.

The scientific creation story is intended to come from research rather than revelation and is therefore subject to its own evolution with gains in scientific knowledge. While much of the world has become convinced that the scientific story as told up to now is worth believing in, it has also led many to despair of the human condition and driven them deeper into, or back to, older religious creation stories that are often seen as opposed to the scientific story but provide meaning, consolation and hope.

We need to understand the depressing aspects of this scientific creation story that have locked us into inequitable economics and environmental degradation, into the belief that science and religion are incompatible, and to see how this story is now changing to give us new hope for a truly better world.

The western science creation story at its simplest comes from physics and biology. Physics begins it, telling us we live in a non-living accidental universe running down by entropy-the steady overall loss of energy ever since the Big Bang-in a universe without meaning or purpose and doomed to an eventual cold nothingness. Biology continues this basic theme by agreeing to the concept of life as negentropy-the organization of living systems that runs counter to entropic disorganization. Unfortunately, the story continues that life cannot overcome entropy but eventually loses to the stronger entropic decline. Further, biology tells us we are doomed to endless competitive struggle in scarcity because that is nature's way of evolution and thus our own human nature.

This is, obviously, a depressing story. It developed most clearly during the two decades from 1850 to 1870 , when Rudolf Claudius formulated the entropy law and Charles Darwin the theory of biological evolution. Though both physics and biology have evolved their stories considerably since then, these essential teachings still prevail as the scientific creation story for our world culture today.

An important social consequence of this scientific story has been to see human life as devoid of any meaning or purpose beyond material acquisition. Another was the retreat from science to religion believing the two to be incompatible. A third, stemming from 
the claim that science is value free, was cultural relativism-the proposal that beliefs and ethical truths only hold relative to a specified culture-a concept now foundering as we recognize that we need basic common values as much as cultural diversity in a time of globalization.

With the blessings of State power, the western scientific story fostered a dominant world culture that increasingly sacrifices the relationship riches of previous human cultures to material consumerism, which is widely advertised even to those who have been made poor in the competitive struggle of our world economy. This highly inequitable consumer culture, taken up by many deeply religious people as well as nonbelievers, is now acknowledged as unsustainable-a term that literally means 'cannot last; must be changed.'

Unsustainability is the prevailing material crisis of the present, with hopelessness our prevailing spiritual crisis. Both are rich in opportunity for our evolution into cooperation.

Scientific belief in a non-living universe is just that: a fundamental belief, an unproven assumption on which western science is built, not a research result. For the founding fathers of western science, who were religious, believing in the universe as a vast mechanism gave them hope of understanding it as the invention of a God in whose image they were made and by whom they were empowered as inventors in their own right. When God was later rejected by western scientists, the belief in a mechanical universe actually became illogical, since mechanisms are assemblies of parts designed to meet their inventors' particular purposes. They simply do not come into being by series of sheer accidents without any designer, purpose or meaning, yet this is how the universe was said to come into being after the overthrow of God. It is this illogic of seeing nature as meaningless, purposeless, accidental machinery that drove me to work on new foundations for western science that would be more compatible with its research findings.

It is interesting to note that the great religions -Judaism, Christianity and Islam- all share a Creator God maintaining an identity apart from His creation, while in eastern religions including Taoism, Confucianism, Vedism, Jainism, Kotodama and Buddhism, nature arises from and within some version of Oneness, an undifferentiated consciousness or cosmic mind that is the source of the material worlds formed within it. These eastern religions have been found very appealing to many of us trained in western science and have given us the keys to our new fundamental assumptions about the universe. I would add that the great desert religions have all had their mystical intellectual thinkers who did not personify their Creator in popular form and came much closer to the concepts of the eastern religions, while the latter, notably Hinduism, developed popular forms with personified gods. 
The word religion comes from the Latin re-ligio, a binding back to source. By this essential definition, even science has the 're-ligio' purpose of revealing and linking us to our origins. Many scholars within the ancient eastern religions, as well as the mystic scholars of the desert religions, were researchers in their own right. Through long and rigorous training, they observed not only the outer world with which western science is concerned but, even more fundamentally, the inner world of the human mind, using formal techniques of meditation to consciously experience, observe and analyse the human mind from within, as well as ultimately connecting or merging it with Cosmic Mind in Oneness.

\section{An Evolving Scientific Story}

World renowned physicist Ervin Schroedinger, in his essay Mind and Matter, first published in 1958, pointed out the strange fact that scientists can only build models of the universe in their conscious minds but then leave that consciousness out of their models. More and more, I meet western scientists who, like myself, have reversed their belief in a material universe giving rise to consciousness in the process of evolution, taking up the entirely opposite belief that consciousness is primary and gives rise to material worlds in evolution, not to mention humans with human consciousness.

Even if they have not yet made this clear reversal in belief, many will acknowledge that all human experience occurs within human consciousness and that scientific models of the universe should therefore be acknowledged as models of a universe seen through human consciousness. If we accept that ants and aliens must necessarily see their universe differently from humans, and that their perspectives must also have validity, our models can include our perceptions of how they see things, insofar as we can see into and thus share at least certain aspects of their experience. The entire process of such efforts to see from multiple perspectives still occurs within human consciousness.

The model of a lifeless, mindless, mechanical universe independent of human experience is a historical construct that originated in the very construct science rejected: that of an external Father God engineer of nature's machinery. The emerging new scientific model acknowledges that the only appropriate definition of reality is the sum total of direct human experience-a definition of reality found in Webster's online dictionary as "non-derivative experience." Human experience is perceived both as an outer world including scientific experiment and as an inner world of thoughts, feelings, emotions, dreams, revelation and intuition. Taking inner experience as seriously as outer, the new breed of scientists is establishing research projects inspired by cultures with long experience in studying inner worlds, thus building important bridges with spiritual traditions. The Dalai Lama's ongoing work with neurological laboratories is a case in point.

This kind of scientific model would help us to understand that each and every human being lives in a uniquely evolving reality shaped by his or her own shifting perceptions, beliefs and values as we seek common values and other common ground while 
respecting our differences. This seems a much more realistic view of things than to continue staging human contests for trying to convince everyone on Earth of any one culture's or science's reality. Moreover, the foundational consciousness in such a scientific model would go far to bridge the current differences between science and spirituality.

As this new version of western science evolved from our different foundational beliefs or assumptions, we gained a new perspective showing everything perceivable in our universe and on our planet as self-organizing, creating itself from within and from a common field of Oneness, clearly related to the relatively newly discovered Zero-Point Energy field in physics. Several new proposals for unified field theories integrate radiation (the primary entropic electromagnetic energy) with centropic or syntropic gravitation in such dynamic balance that no Big Bang and no universal deterioration occurs. See for example the model developed by Nassim Haramein with Elizabeth Rauscher).

In biology, the definition of life called autopoiesis, literally self-creation, states that a living entity is one continually creating and maintaining itself in relation to its surround. While intended for the biological entities science previously recognized as life forms of Earth, I have shown in my book EarthDance: Living Systems in Evolution, as well as in my model of a living universe that it is easily and persuasively extended to Earth as a whole, as well as to the entire self-organizing universe. One of the great advantages of seeing the universe as alive is that the evolution of life from non-life, consciousness from non-consciousness and intelligence from non-intelligence disappear as scientific problems. In a science based on belief in a divinely created living universe these problems never arise. The group of western scientists in which I count myself has been engaged in finding a set of fundamental assumptions for science that include a plausible self-organizing living universe arising within cosmic consciousness.

\section{A New Biology of Earth and Cosmos}

From a biological perspective, we can see the balanced universe as having a metabolism of anabolic buildup and catabolic breakdown and recycling, from the fundamental vortex of a vast proto-galactic cloud in the macrocosm to the tiniest whirling particle in the microcosm, revealing a universe self-organizing and maintaining itself at all levels, alive by the autopoiesis definition. Earth is a giant selforganizing living cell that continually recycles itself from the inside out as magma surfaces and cools into new rock, then melts back in as crustal materials are sucked into deeper magma through tectonic plate activity. Wind patterns, water cycles, sedimentation, decay and other Earth means of recycling its materials as biological creatures evolve fill in the picture of a living Earth.

The giant Earth cell gains ever greater complexity by evolving tiny cells on or near its surface (like the living bark of a giant redwood tree) through the intelligent alliance of DNA, proteins and lipids. Microscopic cells evolve enormous variety and complexity 
by freely exchanging their genetic material as DNA becomes the planetary language of life, permitting blueprints to be encoded and shared among all Earth's creatures from the tiniest single-celled bacteria and funguses to the largest mammals and tallest trees.

Once physics and biology are reconciled in a common universal model, with Earthlife as a special case of additional complexity halfway between the macrocosm and the microcosm, as the ancients intuited and we now can measure, the other fields of science can readily adapt to the new foundational assumptions. Alternative medicine is already becoming mainstreamed; many conferences are organized to further the integration of religious and scientific worldviews. A whole new branch of scientific investigation into the ongoing communion and conscious co-creation among all species and life forms may soon develop, with special attention on indigenous knowledge in this field.

\section{An Integral Evolution Theory}

Perhaps most importantly, evolution biology, as I see it, needs to integrate Charles Darwin's understanding of the importance of competition with Pyotr Kropotkin's understanding of the importance of cooperation, which was as avidly taught in the Soviet Union as Darwin was taught in the evolving capitalist world. I recognized this need when I began to perceive an evolutionary maturation cycle completing itself again and again as species evolved.

Ecologists recognize several different types of ecosystems based on two fundamental ones known as Type I, in which species compete fiercely for territory and resources and Type III, in which species are highly interwoven in complex and mutually beneficial cooperative networks. While the Type I's are characterized as 'pioneer species' and the Type Ill's as 'climax systems', ecologists have not acknowledged something I came to see as obvious: that Type I's exemplify the first or immature phase of species evolution, in which species multiply rapidly, competing creatively and aggressively for resources to establish themselves, while Type Ill's represent a later cooperative phase on an evolutionary learning curve or maturation cycle.

While western science assumptions about nature make it very difficult to see intelligence throughout nature, it seemed to me obvious that species learned from experience, perhaps by trial and error, the economic benefits of forming cooperative alliances in which they feed and nurture each other, evolving the collaboration that permits them to build complex stable ecosystems such as rainforests and prairies, not to mention complex multi-celled creatures in which the cells must necessarily achieve a highly cooperative mode of being.

Note also, that in human cultures as well, individuals are expected to grow out of their competitive if creative adolescent phase to become maturely cooperative members of a stable society. What if the more aggressive human social organizations of today discovered how much cheaper it is to feed your enemies than to destroy them, not to mention the security that comes with making friends of enemies? 
This cyclic evolutionary process of maturation can first be seen in the way the earliest ancient bacteria evolved from a highly creative hostile, competitive mode to a peaceful collaboration that evolved much larger and more complex nucleated cells through a cooperative division of labor among a variety of specialized kinds of bacteria that came to live in community with each other, each of them 'donating' some of their DNA to the central library known as the nucleus. All fungi, plants and animals, including humans, are made from these cell cooperatives to this day the only kind of new cell ever to evolve since bacterial cells evolved. But before multi-celled creatures could evolve as giant cooperatives of cells, the new nucleated cells had to live through their own juvenile phase of hostile and creative competition with each other before evolving into multi-celled creatures by the same process of learning the advantages of a collaborative division of labor.

In every completed cycle a new and much larger unity evolves, within and upon the gigantic Earth cell. I believe that the very same evolutionary cycle is now driving our competitive human nations to collaborate as global family.

Because of this repeating maturation cycle, living entities came to be embedded within one another in what I call (following Arthur Koestler's terminology) holons in holarchy, where holons are living entities operating by the same principles at all size levels: for example the holarchy of the cell organelles (descended from once free-living bacteria) within their nucleated cells, the bodies made of these larger cells, the families in which the bodies live, and their communities, ecosystems, nations and global socioeconomy.

Now, things become really interesting when we combine this notion of holarchy with the evolutionary maturation cycle. For example, when every level of your own body's holarchy from cell to organ, to organ system, to the whole body is able to express and meet its self interest (note: not selfishness), negotiations happen and cooperation evolves through bio-dialogue or communion. It is very important to see that self interest is only destructive when not constrained by the self interest of larger holons that modulate it, or when larger holons fail to understand that their health depends on smaller holons embedded within them.

Every individual human, like every cell in a body, must be supported in meeting their needs, and diversity must be recognized as essential to creativity, while everyone's overarching goal is mature cooperation and mutual sustainability. The World Trade Organization, for example, cannot create a healthy world economy without meeting the expressed self-interests of local economies. Only healthy individuals in healthy families in healthy communities can serve as a basis for a healthy world economy. Healthy living systems are necessarily healthy at all levels of holarchy.

The Soviet Union failed, by my analysis, because it suppressed self-interest in its citizens, thereby killing an important source of motivation and the ability to take 
initiative. Capitalism may fail because individualism has been overdone and juvenile competition has not been adequately encouraged and supported to mature into necessary communal cooperation. Cooperative communities can and should, of course, include friendly competition, as in sports, design and other creativity contests, in order to keep up creativity without hostility.

In my biological model we can also see that Earth's greatest periodic crises-the simultaneous extinctions of many, if not most, life forms-brought about her greatest waves of creativity, each extinction followed by a sudden explosion of new life forms, rather than slow linear Darwinian changes. Not until things were thoroughly shaken up did these novel patterns arise out of the crises, as the fossil record reveals, and the new patterns extended across many life forms at once as if ecosystems evolved as a whole, not species by species. The universal DNA language and a consciousness pervasive in nature permitted them all to commune and share information in adapting to each other.

As another example of how nature includes opposites, such as competition and cooperation, rather than choosing between them, it tends toward conservatism wherever and whenever things are working well and radicalism where they don't. Sharks and cockroaches are so highly adaptable that they have not evolved further for a very long time despite massive changes in their ecosystems, not following the Darwinian model. One might say they are like bicycles in a jet age, still working well despite the newer modes of transport. But when things do go wrong, or a crisis of climate change causes an extinction, nature goes into a radically creative mode, as I just illustrated in talking about entire ecosystems organizing new species after an extinction.

Many research results point the way to this new scientific model of nature in physics, chemistry, biology, medicine and psychology, their evidence accumulating over the past century, needing only to be put into a more holistic context founded on consciousness and universal life. Once this new scientific model described in greater detail that is more widely accepted and publicized around the world, I believe it will release considerable human hope, joy and creativity, inspired by a dynamically balanced and sustainable universe that is not running down at all, and by an inspiring evolution theory showing that the way of the future is not hostile competition in scarcity but creative collaboration and recycling to produce sustainable abundance for all.

\section{Building Global Family}

Humans have known from experience that old, rigidified structures do not change without shaking their very foundations. A butterfly cannot happen without the meltdown of a caterpillar and many cultural stories, such as the phoenix rising from the ashes, have recognized this fundamental pattern. Whole cultures have collapsed before new ones arose; countries destroyed in wars emerged in shiny new forms. Philosophies and beliefs have been challenged, reincorporated in new thought systems, or dissolved and replaced throughout history as human cultures evolved. My favorite Greek 
philosopher, Anaximandros (known as Anaximander in English) left only a single amazing written line describing evolution through recycling Earth's materials, which in my own translation from ancient Greek reads: "Everything that forms in nature incurs a debt that it must pay by dissolving so that other things may form."

History, too, makes sense in this light: understanding thousands of years of competitive empire-building-from expanding kingdoms to colonizing nation states to the empires of multinational banks and other corporations-as the juvenile to adolescent phase of urbanized humanity's socioeconomic and political evolution. (Some non-urbanized Indigenous cultures that remained embedded in nature achieved maturity earlier.) Billions of people who long for a peaceful world today could be helped to see the very real possibility-even probability-of the way ahead to a cooperative global family through this new story of species maturation into peaceful cooperation. And for the many whose worldview is religious, surely this is the will of their God.

As we face the great confluence of crises I spoke of at the beginning of this article, we recognize the need to replace oil with alternative energies. Science can lead the way into massive development of solar, hydrogen, wind, geothermal and other benign forms of power, as well as the necessary conversion of industry from the extremely wasteful 'heat, beat, treat' methods of hydrocarbon-based production to following nature's lead in carbohydrate-based production with zero waste.

New projects for building global family through cooperative enterprises have already cropped up everywhere around the globe, now woven together by the Internet through which they can communicate and strengthen each other. The more than a million NGOs mentioned earlier are working in myriad ways to improve human life, more often than not at the grassroots level. A story can be a powerful catalyst for change, and as the new story of science catches on, they will flourish more and more.

In my travels around the world as an evolution biologist, I see spirits lift and sleeves roll up for the work of building cooperation as I tell this new biological evolution story, showing people that nature is actually on our side: that crises are opportunities for our evolution to cooperative maturity. We humans can follow countless other species to mature collaboration precisely because we have gotten ourselves into such big trouble now!

\section{Evolving Science from Conquest to Consortium}

Thus far, I have described the emergence of a new consciousness-based science from within western science as though it will replace the latter. But that is not my intent. Ever since Thomas Kuhn's mid-20th century classic The Structure of Scientific Revolutions, we have indeed looked for the signs of yet another historic paradigm emerging within western science, the only science legitimating itself, to replace it by preserving its methodology while changing its foundational assumptions, its formal worldview. Indeed, we can now identify the one I have described, which shifts our 
picture of the universe from one in which consciousness is the late emerging product of a non-living material universe to one that recognizes the universal primacy of consciousness in a living universe.

Kuhn's model of scientific revolutions, however, seems to me to belong to the juvenile mode of my evolutionary maturation cycle, exemplifying the conquest mode of a new paradigm killing off and replacing the old after a period of competition. My view of evolution biology, as described in this article, clearly makes this obsolete. In its place I propose an alternative model considered in the 2008 Hokkaido Symposium on the Foundations of Science that better fits our globalizing world, as well as my own conceptualisation of evolution as a maturation process from hostile competition to mature collaboration.

Not the least of the arguments for this is that western science should not be abandoned because it has proven itself again and again in amazing experiments on the nature of nature, as well as by spawning wonderfully useful technologies from steam engines to locomotives, to internal combustion engines, global electric systems, medical equipment, microscopes, telescopes, genome readers, telephone systems, television, computers, space vehicles, iPods, and so many more.

The problem is that because it does not see nature as conscious and intelligent throughout, it has led the entrepreneurial business world to see nature as no more than an array of resources for human use and has thus been taken into areas of life such as genetic 'engineering' and other hi-tech agricultural initiatives heavily based on fossil fuels and their derivative toxic chemicals that may be doing us more harm than good because of the failure to understand living systems adequately. And, as I pointed out in this article, its fundamental 'creation story' has been depressingly hopeless, inspiring a consumer culture with which to comfort ourselves as the meaningless, purposeless universe runs down.

What I thus proposed at the symposium was that we promote the concept of recognizing the unique sciences of different cuktures that could engage in sharing and mutual friendly critique as equal participants in a global consortium of sciences. The fundamental difference between these sciences would lie in their publicly stated fundamental assumptions about the universe and nature as known on Earth, and how these can be studied scientifically: i.e., the scientific worldview of each science, formally stated. Only upon such a foundation of assumptions can we posit scientific theories and testable hypotheses; there is no other way to build a science, however little this crucial matter is still understood in the world at large. In the differing worldview of each such science, it will be natural to ask different questions, to posit different kinds of theories and hypotheses, so we would stand to get a far richer knowledge base than is possible within a single science. 
I repeat, because this is so important, that no science is possible without a set of fundamental cultural assumptions. Because western science has risen virtually unchallenged to global hegemony, many western scientists-no matter where in the world they were trained, as all leading universities globally teach western science-have forgotten, or have never even thought about, their fundamental assumptions, which are considered the domain of philosophy of science, now relatively rare in university curricula.

It is no more and no less valid to hold a living universe as a fundamental assumption than a non-living universe. Similarly, consciousness, without which there could be no kind of shareable knowledge, and therefore no science, can equally legitimately be assumed as primary to material worlds or as their late emergent product. These are just two assumptions on which differences in scientific foundations have become obvious; at the symposium we listed dozens of such basic assumptions for each of the two sciences we considered.

In speaking to Islamic audiences, I have suggested that Islamic science-a very old science rooted in ancient Arabic and Greek and Egyptian sciences, if not others from the farther East as well-reclaim its legitimacy. The best strategy for doing this seems to me to find domains in which it can excel that have been overlooked by western science and that would be important to the world at large.

Since science is the formalized study of nature, some aspect of nature not yet studied adequately would need to be found. One such, I further proposed, would be economics, which until now has not been the domain of science but of economists with rather unscientific entrepreneurial worldviews and purposes, with a smattering of sociology in the prevailing belief of economists in the selfishness of individuals, fundamental to their models.

It has long been obvious to me that nature is the great expert on economics, defined as the transformation of natural resources into useable products that are distributed and consumed, with any remains (called 'wastes' by humans) recycled in a sustainable (zero-waste) economy.

Our own highly evolved multi-cellular bodies are composed of up to a hundred trillion cells, each of which, at its nanolevel, is as complex as a large human city, and in each of which there are now known to be some 30,000 recycling centers renewing our proteins, the major constituent of our bodies. Further, these recycling centers are so sophisticated that they can be compared to chipper machines that issue a new tree in place of each dead or ill tree fed into them!

In each cell, as well, there are some thousand mitochondrial 'banks' issuing free storedvalue credit cards of ATP currency spent on every single molecular chemical transaction in that city-complex cell. When the credit limit is spent, the card goes back 
to the bank for a new credit line; no repayment required, much less an interest charge. These 'banks' economic role is to monitor the amount of currency needed to maintain balance in the cellular, and thus body, economy by adjusting the credit lines.

Every cell in our bodies is nourished equally by the food, air and water we take in; each is supported in its own role, and no organ can hoard wealth while depriving other organs. Similar situations occur inhealthy mature ecosystems, where every species has its unique but critical role in maintaining the whole.

This is only a small taste of what such an Islamic economic science would find in the mature ecosystems of nature. Further, I assume that unlike western science, Islamic science would not deny values and ethics as part of science but would insist on their inclusion. And I would hope that Islamic science would recreate and expand on the marvelous scientific tradition of developing gardens in deserts and otherwise living very comfortably in them through highly effective natural cooling and night-heating systems, appropriate architecture, etc. as our planet heats up and more and more populations would benefit from such science.

Similarly, I would encourage the revival and evolution of the ancient sciences of India, Tibet, etc, to reclaim their legitimacy and modernize their amazing ancient understanding of the human mind, as I would encourage indigenous sciences that include very impressive medical, astronomical, agricultural and other scientific domains to join the consortium, and I would make room at the table for young people who may be interacting with outer space beings that have yet a different take on the universe/nature to develop more sciences accordingly as their worldview expands.

I believe such a consortium of sciences would be one of the most valuable things we could do to role-model cooperation in the larger process of peaceful globalisation that is our evolutionary mandate. Further, I am persuaded that it would make enormous contributions as we put our heads together collectively, across all cultures, to solve the current confluence of great economic crises and find ways to thrive even on a hotter planet. 


\section{References}

Haramein N. \& E. A. Rauscher. (2004). The Origin of Spin: A Consideration of Torque and Coriolis Forces in Einstein's Field Equations and Grand Unification Theory. The Resonance Project Foundation: USA. www. theresonanceproject.org/research/torquepaper.pdf (Accessed June 2004)

Dugatkin L. A. (2011). The Prince of Evolution: Peter Kropotkin's Adventures in Science and Politics. CreateSpace

Kuhn T. (1996). The Structure of Scientific Revolutions. 3rd ed. University of Chicago Press: USA.

Sahtouris E. (2005). The Biology of Business: New Laws of Nature Reveal a Better Way for Business. VIA Journal. (e-journal) 3 (1). Available through www. viavisioninaction.org. [Accessed June 2004].

Sahtouris E. (2008). Science Evolving Hokkaido Foundations of Science Symposium Breaks New Ground, http://www.sciencevolve.com/(Accessed June 2004)

Sahtouris E. \& J. E. Lovelock. (2009). EarthDance: Living Systems in Evolution. iUniverse.

Schroedinger E. (1958). Mind and Matter. Cambridge University Press. 